\title{
Maudsley Community Item Sheet
}

\section{Clinical data registration system for child guidance clinics}

\author{
Richard J. Corrigall and Anula Nikapota
}

\begin{abstract}
The Bethlem Royal and Maudstey Hosplitals Item Sheet system for registering clinical data generated by psychiatric assessments is long established, with a proven track record as an instrument of scientific research. However, its use has not spread beyond the originating institution, desplte being avallable in the public domain for many years. To address this problem we have designed a modified version of the litem Sheet. The new system has been simplified and improved to facillitate the use of this research aid in child guidance clinics and similar settings.
\end{abstract}

The Bethlem Royal and Maudsley Hospitals clinical data registration system, or 'Item Sheet' (Thorley, 1982) has been in use for nearly three decades. The register allows the systematic capture of data from psychiatric assessments, and provides a summary of demographic characteristics, diagnosis, symptomatology, treatment and outcome. The clinical ratings within the register have been shown to be of acceptable reliability (Goodman \& Simonoff, 1991). The Item Sheet has proved to be of great value in research, both as a direct source of data for analysis (e.g. Harrington et al, 1990; Simonoff, 1992; Goodman \& Richards, 1995; Hollis, 1995) and as an instrument for case selection. A CD-ROM search of publications in the field of child and adolescent psychiatry over the past 14 years, undertaken by the authors, indicated the Maudsley Item Sheet had been cited as a data source more often than any other clinical data collection system. However, all of these studies had originated in the Maudsley and Bethlem Hospitals. Thus, the Item Sheet has proven value as an instrument in scientific research, but its use does not appear to have disseminated beyond the originating institution, despite having been in the public domain for 14 years. The experience of the authors in a child guidance clinic suggested that this might, in part, have resulted from certain 'unfriendly' characteristics of the Item Sheet system that have impaired its ease of use. The original was designed to be completed by medical staff and was intended to be compatible with the extended, multi-disciplinary assessments of a tertiary service. However, in the Brixton Child Guidance Clinic it proved to be unpopular, particularly with non-medical staff, who found the form lengthy and difficult to complete. We have, therefore, designed a revised form of the Item Sheet. This has mainly involved reduction and simplification, while retaining core information and preserving compatibility with the original, although some areas have been expanded in order to improve the relevance of the instrument in a community setting. It is hoped that this revised Item Sheet may be more readily applicable in settings outside of the Maudsley and Bethlem hospitals, and thus broaden the accessibility of the Item Sheet system as a research tool.

\section{Item Sheet}

Copies of the revised Item Sheet are available upon request from the authors. The original three-part structure has been simplified to two parts. Part $I$ is completed soon after the first assessment and Part II is completed at closure.

The layout has been improved in order to reduce the time required to fill in responses, particularly when large numbers of negatives are being entered. A number of items have been updated and in some cases modified, to take account of practice in community settings. The headings employed in the ethnicity section were selected as those most likely to be encountered in the local population but may need to be modified if the system is used in other areas.

The principle of a multi-axial classification is retained in the Maudsley Community Item Sheet, using a modified version of the ICD-10 multiaxial system (World Health Organization, 1996). The requirement to fill in a coded psychiatric diagnosis for axis 1 can be daunting for nonmedically trained staff. A list of psychiatric syndromes has, therefore, been derived from the ICD-10 classification by a senior member of the academic staff of the Maudsley Hospital, with the aim of simplifying the range of choice while retaining the categorical distinctions most likely to be of interest in research. In the clinic where the Item Sheet was developed, non-medical staff received training in the recognition of common 
psychiatric syndromes, such as conduct disorder, so that reliable diagnoses of such conditions could be made by all staff. Where less common or more complex psychiatric diagnoses are suspected, staff would be expected to consult with psychiatric colleagues before completing the Item Sheet. Ready access to a shortened version of the ICD-10 manual may also be of value in assisting non-medical staff to determine diagnostic codes (World Health Organization, 1994).

A significant innovation in the new Item Sheet has been to devise an improved system for the recording of psychosocial functioning. This element of assessment is of particular relevance in the child guidance setting, where maladaptive functioning, rather than psychiatric symptomatology per se, is often the reason for referral. Furthermore, detecting changes in psychosocial function is likely to be valuable when attempting outcome research. The ICD-10 multi-axial system includes an axis for psychosocial functioning, based on the Children's Global Assessment Scale (Shaffer et al, 1983). However, the use of a single, overall rating of functioning is not sensitive to patterns of domain-specific malfunction, which may be of clinical and research interest. Furthermore, when used longitudinally, deterioration in one domain may be masked by improvement in another, while changes occurring in one domain only may be obscured in the global rating. For these reasons a system has been employed of separate rating in four key domains of psychosocial function: home life. school life, peer relationships and social behaviour. Three main codes are available for each of these domains. An attempt has been made to operationalise these categories, with guidelines included in the body of the data registration form.

\section{Conclusions}

The field of medical data collection has expanded greatly in recent years. The Korner Information System (Steering Group on Health Services Information, 1982) was introduced into the health service in the 1980 s and lead to the development of a variety of health information systems around the country, including systems supporting mental health services (Lelliot et al, 1993) and systems specifically tailored to child psychiatry (Berger, 1989, 1991). Furthermore, a core data set for auditing child psychiatric services has been proposed by the Association of Child Psychology and Psychiatry. The main purpose of such systems has been to facilitate health service administration and clinical audit, rather than scientific research. Indeed, in the light of the Government White Paper, Working for Patients', even greater emphasis is being placed on the demands of cost analysis and resource allocation (Information Management Group, 1990). In contrast, the Bethlem Royal and Maudsley Hospitals Item Sheet is primarily a research instrument. This should be borne in mind when comparing the Item Sheet system with alternative clinical information systems. Thus, although the system does yield valuable administrative and audit information, its main strength lies in its proven efficacy as a valid source of data for scientific research.

Our experience at Brixton Child Guidance Clinic has indicated that the new Item Sheet is more acceptable to staff than the original, with a significant increase in rates of completion since its introduction. The new system for recording of psychosocial functioning is substantially different from the original. A formal evaluation of the reliability and validity of this component is currently underway.

\section{Acknowledgements}

Dr Fiona Subotsky and Professor Eric Taylor made substantive contributions to the first draft of the revised Item Sheet and the multi-disciplinary team of Brixton Child Guidance Clinic assisted in its development.

\section{References}

BERGER, M. (1989) Dual-function clinical database simplifies records. British Joumal of Healthcare Computing, 6, 26-27.

- (ed.) (1991) Aspects of Audit: Collecting and Using Clinical Information, Occasional Paper 4. London: Association for Child Psychology and Psychiatry.

GoODMAN, R. \& SimONOFF, E. (1991) Reliability of clinical ratings by trainee child psychiatrists: a research note. Journal of Child Psychology and Psychiatry, 32. 551555.

- \& RichaRDS, H. (1995) Child and adolescent psychiatric presentations of second-generation Afro-Caribbeans in Britain. British Journal of Psychiatry. 167. 362-369.

HARRINGTON, R., FUDGE, H., RUTTER, M., et al (1990) Adult outcomes of childhood and adolescent depression. I. Psychiatric status. Archives of General Psychiatry. 47. 465-473.

Holus, C. (1995) Child and adolescent (juvenile onset) schizophrenia: a case control of premorbid development impairments. British Journal of Psychiatry, 166, 489495.

INFORMATION MANAGEMENT GROUP, DEPARTMENT OF HEALTH (1990) Part of NHS Management Executive Working for Patients: Framework for Information Systems: Information. Overview: The NHS Review Working Paper 11. London: HMSO.

Lelloot, P., Flanagan, C. \& Shanks, S. (1993) A Review of Seven Mental Health Information Systems: A Functional Perspective. London: Royal College of Psychiatrists.

SHAFFER. D., Gould, M. S., BRASIC, J., et al (1983) A children's global assessment scale (C-GAS). Archives of General Psychiatry. 40. 1228-1231. 
SimonofF, E. (1992) A comparison of twins and singletons with child psychiatric disorders: an item sheet study. Journal of Child Psychology and Psychiatry, 33. 1319 1332.

SteEring Group on Health SERVICEs Information (1982) First Report to the Secretary of State. National Health Service. Department of Health and Social Services. London: HMSO

THORLEY, G. (1982) The Bethlem Royal and Maudsley Hospitals' clinical data register for children and adolescents. Joumal of Adolescence, 5. 179-189.

WORLD HEalth ORganization (1994) Pocket Guide to the ICD-10 Classification of Mental and Behavioural Disorders. Edinburgh: Churchill Livingstone.
- (1996) Multiaxial Classification of Child and Adolescent Psychiatric Disorders. Cambridge: Cambridge University Press.

*Richard J. Corrigall, Consultant Psychiatrist, Simmons House Adolescent Unit, St Luke's Woodside Hospital, Woodside Avenue, London N10 3HU, and Anula Nikapota, Consultant Psychiatrist, Brixton Child Guidance Clinic, 19 Brixton Water Lane, London SW2 1NU

*Correspondence

\section{Management of Imminent Violence}

\section{Clinical Practice Guidelines to Support Mental Health Services}

Prepared by the College Research Unit, this report publishes the findings of the most comprehensive and systematic review yet of research into the management of violence in clinical settings. It sets guidelines for clinical practice to be implemented in hospitals and psychiatric units throughout the UK and will be of interest to colleagues overseas who are seeking guidance in this area. The guidelines will form the basis of a national multi-centre clinical audit being organised by the College Research Unit later this year.

\section{Key features:}

- Guideline statements supported by a series of implementation points, offering practical suggestions as to how the recommendations may be incorporated into every day practice

- Extensive information on disseminating and implementing the guideline statements with the use of checklists and action plans

- A 'lessons learned chapter' including a discussion on the limitations of the research papers examined

- A glossary of terms and full references of publications reviewed

In recognition of the importance of these guidelines and in order to promote good practice and ensure implementation, the College will be producing a guideline 'checklist' for every day use. This will be distributed throughout the NHS.

March 1998, Occasional Paper 41, ISBN 1-901242-13-7, Price £20.00

(£10.00 to Members of the Royal College of Psychiatrists quoting Membership No.), 104 pages

\section{To order:}

Please send your order to the Book Sales Department, Royal College of Psychiatrists, 17 Belgrave Square, London SW1X 8PG. Tel: +44 (0) 171235 2351, ext 146,

Fax: +44 (0) 171259 6507, email: booksales@rcpsych.ac.uk

\section{ROYAL COLLEGE OF PSYCHIATRISTS COLLEGE RESEARCH UNIT}

